\title{
Sexual Activity and Older Adults: Stigma, Overall Health, and Research
}

\author{
Samantha Tupy, M.A., Clinical Psychology, Idaho State University \\ Matthew Schumann, M.A., Clinical Psychology, Idaho State University \\ Xiaomeng Xu, PhD, Experimental Psychology, Idaho State University
}

\section{Introduction}

With the growing population of older adults (age 65+), there remains a significant lack of understanding and research within this group. Specifically, data regarding sexual activity of older adults is quite limited (Kleinplatz, 2008). This gap in research remains with no clear strategy to improve sexual health for older adults in the United States (Swartzendruber \& Zenilman, 2010). Thus myths and stigma regarding older adult sexuality exist due to this lack of knowledge (Butler, 1969; Nelson, 2005; Robb, Chen, \& Haley, 2002).

These false beliefs are prevalent, and are often endorsed by older adults. In laboratory (Hausdorff, Levy, \& Wei, 1999), cross-sectional (Stewart, Chipperfield, Perry, \& Weiner, 2012) and longitudinal (Levy, Slade, \& Kasl, 2002; Levy \& Meyers, 2004) research, associations between negative self-directed stereotypes and adverse health behaviors have been consistently established. Providers holding negative stereotypes about aging often miss important information regarding sexual health (Hillman, 2012). Specifically, providers may assume older adults are not sexually active thus missing diagnoses related to sexually transmitted infections (STIs). Incorrect assumptions lead to avoidance of discussing sex in a positive or normative manner, resulting in reduced quality of sexual health and quality of life $(\mathrm{QoL})$. The purpose of this paper is to provide a summary of current empirical research on older adult sexuality. The goal is to challenge misunderstandings, stereotypes, and stigma associated with older adults to promote an open dialogue about an important aspect of life with several treatment and assessment implications.

\section{Myths and Their Health Implications}

Prevalent stereotypes such as "older adults are not interested in sex" or "older adults should not be concerned with STIs" are salient examples of myths serving as barriers to proper healthcare. The Center for Disease Control and Prevention (CDC) 2015 screening guidelines recommend screening adults aged 13 to 64 years old (Center for Disease Control and Prevention [CDC], 2015). However, older adults rarely receive comprehensive health screens. Adults aged 50 and older accounted for an estimated 18\% of the HIV diagnoses in 2013 and "accounted for $27 \%$ of the 26, 688 AIDS diagnoses in the United States" (CDC, 2015; HIV and AIDS Diagnoses and Deaths section, para. 3). Chlamydia, syphilis, herpes simplex virus, and gonorrhea are also frequently identified within this population (Jena et al., 2010). Unfortunately, many older adults go untested, and if diagnosed it is often in the later stages of the illness. As with most illnesses, later diagnoses often results in poorer prognosis. Improper education regarding the aging 
process is a core reason why myths and stereotypes continue to perpetuate and often result in exacerbation of other symptoms and variables such as depression, anxiety, infections, and other chronic health conditions. Ignored symptoms such as sexual dysfunction or lack of interest may be a sign of an underlying illness, disorder, or infection.

Why might these issues exist and go unnoticed? Stereotypes regarding aging processes and associated stigma of sexual activity are often to blame. For example, providers frequently do not discuss sexual activity with older adults (Gott \& Hinchliff, 2003; Tessler et al. 2007). Older adults, more often than not, will not broach the topic with their provider (Gott \& Hinchliff, 2003). Reasons for not bringing their concerns to the provider are assumptions that sexual activity past a "certain age" is disparaged, or that sexual dysfunction is expected with aging. Research has shown that $72.6 \%$ of men and $70.8 \%$ of women believe sexual dysfunction is part of aging, and many believe it is not treatable (Moreira et al., 2005).

Kaas (1981) suggested older adults might internalize stereotypes and conform in a self-fulfilling prophecy (cited in Hillman, 2012). Thus, if older adults are expected to not talk about sex, they won't. However, it is not as if patients hope providers will avoid the question. An interesting discovery by Moreira and colleagues (2005) was that $54.2 \%$ of men and $44.7 \%$ of women surveyed reported wishing their provider would routinely ask about sexual function. Yet another study identified only $38 \%$ of men and $22 \%$ of women had conversed with their provider about sexual activity after the age of 50 (Tessler-Lindau et al., 2007). The stereotype that older adults are not sexually active, or the stigma that they should not be, has resulted in exclusion from sexual health studies (Gott \& Hinchliff, 2003). A pervasive misunderstanding of aging may perpetuate older adult sexual stigma in clinical, research, and general public domains. Dissemination of empirically supported findings regarding aging sexual activity is the first step to facilitate needed change.

\section{Facts about Aging Sexual Activity}

Aging is a gradual process. The changes are not abrupt and with close monitoring are rarely unforeseen. Even in advanced age, intimacy and sexual activity remain an important component of health and QoL (Camacho \& Reyes-Ortiz, 2005). Gott and Hinchliff (2003) noted that adults aged 70 and older rated sexual activity as less important than those 60 and younger; however, this was due to barriers (e.g., untreated conditions, medication interactions) and not age (Gott \& Hinchliff, 2003). In fact, according to Tessler-Lindau and colleagues (2007), of the adults aged 75 to 85 years old surveyed, 54\% were sexually active, often engaging in some form of sexual activity two to three times a month. Surprising to many, of those older adults, $23 \%$ were sexually active once a week or more. Of those without a sexual partner, $55 \%$ of men and $23 \%$ of women reported masturbating. Regarding those with a sexual partner, $52 \%$ of men and $25 \%$ of women reported masturbating. Of the older adults who reported being single, $22 \%$ of the men and $4 \%$ of the women remained sexually active despite their single status (Tessler-Lindau et al., 2007). Further, Tessler-Lindau and colleagues (2007) uncovered an interesting finding that older adults reported sexual activity similar to adults aged 18 to 59, contradicting the long-standing stereotype "older adults have less sex."

It is important to note health issues are associated with a reduction in interest and ability to engage in sexual activity (Hillman, 2012). Older adults may avoid sexual activity, due to a 
variety of reasons. Diabetes, heart conditions, and cancer are all common conditions associated with decreased sexual activity (Laumann, Paik, \& Rosen, 1999), as well as inaccurate fears of injury, heart attack, or lacking desire associated with medication use. Tessler-Lindau and colleagues (2007) estimated 50\% of older adults have at least one sexual problem, and 33\% have at least two (Tessler-Lindau et al., 2007). In addition, $25 \%$ of older adults with sexual related difficulties avoid all sexual activity, rather than seeking assistance (Tessler-Lindau et al., 2007).

\section{Assessment and Treatment Considerations}

It is imperative that providers obtain ongoing education regarding older adult sexual activity, as well as appropriate assessments and interventions. Inquiring about sexual activity provides insight into a variety of different physiological, psychological, and social concerns of the patient. Including how the patient perceives their body, social expectations regarding sexual activity, health, and knowledge regarding aging (Hillman, 2012). It is often the case that sexual activity and health are inextricably linked. By acknowledging this link, stigma regarding sexual activity can be reduced. Further, this conversation allows the provider to discuss safer sex practices, as many older adults frequently forgo the use of contraceptives for various reasons. However, the two most common reasons are that females are postmenopausal (lack of pregnancy risk), and many have not obtained safer sex education. Yet older adults are at heightened risk for STIs due to decreased immune functioning, thinning of the vaginal wall tissue, and an increase in vaginal tears due to decreased lubrication (Hillman, 2012).

Asking patients about their sexual activity would allow for prevention, identification, and treatment of STIs. Further, this discussion would be a step towards dissolving myths surrounding older adult sexual activity and aging processes, as well as identifying potential underlying health issues. The majority of older adults stated they have either reduced or stopped sexual activity due to barriers relating to function (Laumann et al., 2005). Identification of these barriers would assist intervention efforts. This may foster increased QoL, improve intimate relationships, and overall health outcomes.

Taking these recommendations into account, each interaction with older adult patients should include a respectful and non-judgmental assessment of current and historical sexual health. It is recommended to ask direct questions to avoid uncertainty of how one "should" answer. It is also important to educate patients about sexual health and aging. A provider should take into consideration how to appropriately discuss sexual health with a patient if another individual is present (e.g., adult child, or friend). To protect privacy and provide a safe environment the patient should be asked questions regarding their health (and specifically sexual health) in privacy. When a patient is asked private information with someone present they may be less inclined to speak honestly and ask questions (Hillman, 2012).

\section{Future Research}

Many negative stereotypes regarding aging pertain to older adult sexuality (e.g., older adults do not/should not engage in sexual activity). Research has demonstrated that individuals that hold negative self-perceptions of aging tend to engage in less health maintenance behaviors such as 
regular health check-ups (Stewart et al., 2012). From a clinician perspective, holding stereotypical views impacts the level of care and may result in omitting important sexualityrelevant factors in case conceptualization. From an intervention standpoint, clinicians should be trained to provide sexual education regarding accurate information on the topic of older adult sexuality as a means to replace address negative aging-related stereotypes. Healthcare providers should be encouraged to engage in open conversations regarding sexuality in a positive way. Future research should focus on the physiological, psychological, and social impact of promoting sexual health and challenging negative stereotypes for older adults. Further empirical inquiries should determine whether older adults favor clinicians that broach topics of sexuality in a positive way, and whether this influences future sexual health screening.

Current research on older adult sexuality has primarily focused on cross-sectional methods. There is a paucity of research that focuses on cohort effects or change in sexual attitudes over time. Thus, longitudinal studies are needed to determine to what extent sexual attitudes and behaviors change. Given that sexual satisfaction has been associated with QoL (Chao, et al., 2011), interventions for older adults should aim not only to reduce risky sexual behavior, but also improve life satisfaction.

A vast majority of empirical research on older adult sexuality focuses on heterosexual relationships, but research is also needed on homosexual relationships. Sexual minorities are vastly underrepresented in most empirical literature, and the same can be said for the older adult population. Another important aspect of sexual activity is the role of sexual dysfunction as a drug side effect. As many as $36 \%$ of older adults age 75 to 85 take five or more prescription medications with 46\% concurrently using over-the-counter medications (Qato et al., 2008). Further research is needed to determine how prescription drug use affects older adult sexual behavior, and appropriate remedies.

With regard to assessment and treatment, more extensive training regarding sexual health is needed. A recent study revealed that providers that held negative attitudes and lacked sexuality education were less likely to assess sexual health (Flaget-Greener, Gonzalez, \& Sprankle, 2015). Therefore, future research should compare differing levels of professional education and training in sexual health to determine if this lack of training is associated with patient satisfaction and proper care. This could potentially lead to promotion of better training programs to ensure sexual health is addressed.

\section{Conclusion}

Older adult sexual stigma is a concern for providers due to the negative impact on overall health and QoL. Education regarding sexuality is needed for adequate care and ideally would reduce, if not remove, ageism from assessment and treatment. Providers are encouraged to adopt a positive sexuality perspective and initiate conversations about sexual health, regardless of age. In addition, educating patients regarding the aging process is one mechanism to avoid internalization of stereotypes. Normalizing sexuality and providing a positive perspective toward older adult sexual health could potentially prevent, as well as reduce, STIs in this population and increase sexual satisfaction and QoL. 
Research is another avenue to break down stereotypes and further educate about aging and sexual health. Older adults need to be included in samples to increase knowledge for this population. This is important for several reasons, but in particular the older adult population is on the rise, and living longer healthier lives. Eradication of stereotypes may assist the need for education and promoting high QoL within the older adult population.

\section{References}

Butler, R. N. (1969). Ageism: Another form of bigotry. Gerontologist, 9, 243-246.

Camacho, M.E., \& Reyes-Ortiz, C.A. (2005). Sexual dysfunction in the elderly: age or disease? International Journal of Impotence Research, 17, S52-S56.

Chao, J. K., Lin, Y. C., Ma, M. C., Lai, C. J., Ku, Y. C., Kuo, W. H., \& Chao, I. C. (2011). Relationship among sexual desire, sexual satisfaction, and quality of life in middleaged and older adults. Journal of Sex \& Marital Therapy, 37(5):386-403.

Centers for Disease Control and Prevention (CDC), Division of HIV/AIDS Prevention. HIV Among People Aged 50 and Over, (2015). (Last updated: 5/12/2015) Retrieved from http://www.cdc.gov/hiv/group/age/olderame ricans/index.html

Corrigan, P., \& Kosyluk, K. A. (2013). Erasing the stigma: Where science meets advocacy. Basic and Applied Social Psychology, 35, 131-140.

Flaget-Greener, M., Gonzalez, C. A., \& Sprankle, E. (2015). Are sociodemographic characteristics, education and training, and attitudes toward older adults' sexuality predictive of willingness to assess sexual health in a sample of US psychologists? Sexual And Relationship Therapy, 30(1), 1024.

Gott, M., \& Hinchliff, S. (2003). Barriers to seeking treatment for sexual problems in primary care: a quality study with older people. Family Practice, 20(6), 690-695.

Hausdorff, J.M., Levy, B.R., \& Wei, J.Y. (1999). The power of ageism on physical function of older persons: Reversibility of age-related gait changes. Journal of the American Geriatrics Society, 47, 136-1349.

Hillman, J. (2012) Sexuality and aging: clinical perspectives. Retrieved from http://link.springer.com.ezproxy.mnsu.edu/b ook/10.1007\%2F978-1-4614-3399-6

Jena, A. B., Goldman, D. P., Kamdar, A., Lakdawalla, D. N., \& Lu, Y. (2010). Sexually transmitted diseases among users of erectile dysfunction drugs: Analysis of claims data. Annals of Internal Medicine, 153, 1-7.

Kaas, M. J. (1981). Geriatric sexuality breakdown syndrome. International Journal of Aging \& Human Development, 13, 71-77.

Kleinplatz, P. J. (2008). Sexuality and older people. BMJ : British Medical Journal, 337(7662), 121-122.

Laumann, E.O., Nicolosi, A., Glasser, D.B., Paik, A., Gingell, C., Moreira, E., \& Wang, T., for the GSSAB Investigators Group. (2005). Sexual problems among women and men aged $40-$ $80 \mathrm{y}$ : prevalence and correlates identified in the Global study of sexual attitudes and behaviors. International Journal of Impotence Research, 17, 39-57.

Laumann, E.O., Paik, A., \& Rosen, R.C. (1999) Sexual dysfunction in the United States: prevalence and predictors. Journal of the American Medical Association, 281(6): 5371174.

Levy, B.R., \& Myers, L.M. (2004). Preventative health behaviors influenced by self perceptions of aging. Preventative Medicine, 39, 625-629.

Levy, B.R., Slade, M.D., \& Kasl, S.V. (2002). Longitudinal benefit of positive selfperceptions of aging on functional health. Journal of Gerontology: Psychological Sciences, 57B, P409-P417.

Moreira, E.D., Hartmann, U., Glasser, D.B., Gingell, C., for the GSSAB Investigators Group. (2005) A population survey of sexual activity, sexual dysfunction, and associated help-seeking behavior in middle-aged and older adults in Germany. European Journal of Medical Research, 10, 434-443.

Nelson, T.D. (2005). Ageism: Prejudice against our future self. Journal of Social Issues, 61, 207-221.

Qato, D. M., Alexander, G. C., Conti, R. M., Johnson, M., Schumm, P., \& Lindau, S. T. (2008). Use of prescription and over-thecounter medications and dietary supplements among older adults in the 
United States. Journal of the American Medical Association, 300 (24), 2867-2878.

Robb, C., Chen, H., \& Haley, W.E. (2002). Ageism in mental health care: A critical review. Journal of Clinical Geropsychology, 8(1), $1-12$.

Stewart, T. L., Chipperfield, J. G., Perry, R. P., \& Weiner, B. (2012). Attributing illness to 'old age': consequences of a self-directed stereotype for health and mortality. Psychology \& Health, 27 (8), 881-897.

Swartzendruber, A., \& Zenilman, J. M. (2010). A national strategy to improve sexual health. Journal of the American Medical Association, 304, 1005-1006.
Tessler-Lindau, S., Scumm, L.P., Laumann, E.O., Levinson, W., O'Muircheartaigh, C.A., \& Waite, L.(2007). A study of sexuality and health among older adults in the United States. New England Journal of Medicine, 357(8), 762-774.

Weiner, B. (1985). An attributional theory of achievement motivation and emotion. Psychological Review, 92, 548-573.

Weiner, B. (1995). Judgments of Responsibility: A Foundation for a Theory of Social Conduct. The Guilford Press. 